\title{
Immune Complex Membranoproliferative Glomerulonephritis Associated with Transjugular Intrahepatic Portosystemic Shunts in Alcoholic Cirrhosis: Two Case Reports
}

\author{
Julio Hernández-Jaras ${ }^{a} \quad$ Jordi Espí-Reig ${ }^{a} \quad$ Rafael Alis $^{a} \quad$ Ana-Maria García-Martínez ${ }^{b}$

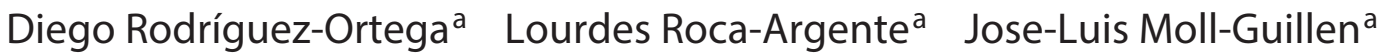

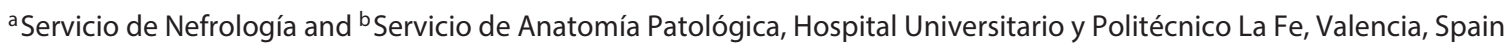

\section{Significance of the Study}

- Transjugular intrahepatic portosystemic shunt (TIPS) placement in one patient was successful without immediate complications, while the other patient was referred for a combined liver-kidney transplant. The TIPS could have caused the immune complex membranoproliferative glomerulonephritis experienced by the patients. Therefore, physicians should be aware of the probability of kidney damage in patients receiving TIPS.

\section{Keywords}

Membranous glomerulonephritis · Membranoproliferative glomerulonephritis · Transjugular intrahepatic portosystemic shunt - Portosystemic shunt · Hepatic cirrhosis

\begin{abstract}
Objective: To report on 2 patients with alcoholic cirrhosis who were treated with transjugular intrahepatic portosystemic shunt (TIPS) placement. Clinical Presentation and Intervention: The 2 patients had a history of alcoholic cirrhosis, and TIPS surgery was performed on them. In both cases, 4 months after TIPS placement, proteinuria was observed along with histological alterations characteristic of immune complex membranoproliferative glomerulonephritis (MPGN). Conclusion: The TIPS in one patient was successful
\end{abstract}

\begin{tabular}{ll}
\hline KARGER & (c) 2017 S. Karger AG, Basel \\
$\begin{array}{l}\text { E-Mail karger@karger.com } \\
\text { www.karger.com/mpp }\end{array}$ & $\begin{array}{l}\text { This is an Open Access article licensed under the terms of the } \\
\text { Creative Commons Attribution-NonCommercial 3.0 Un- } \\
\text { ported license (CC BY-NC) (www.karger.com/OA-license), } \\
\text { applicable to the online version of the article only. Distribu- } \\
\text { tion permitted for non-commercial purposes only. }\end{array}$
\end{tabular}

without immediate complications, while the other patient was referred for a combined liver-kidney transplant. In both cases, immune complex MPGN might have developed after TIPS placement probably due to a reduced immune complex clearance.

(c) 2017 S. Karger AG, Basel

\section{Introduction}

Transjugular intrahepatic portosystemic shunt (TIPS) insertion is a nonsurgical method that decompresses the portal circulation to treat portal hypertension [1]. This technique consists of the creation of a channel through the hepatic parenchyma, connecting one portal vein branch with one hepatic vein, thereby creating an intrahepatic portocaval shunt. Using this technique, the intra-

Julio Hernández-Jaras, MD, PhD

Servicio de Nefrología, Hospital Universitario y Politécnico La Fe Avda. de Fernando Abril Martorell 106

ES-46026 Valencia (Spain)

E-Mail Hernandez_jul@gva.es 
hepatic vascular resistance decreases, and this causes a pressure reduction in the extrahepatic portal venous system. Therefore, TIPS is used to treat secondary complications of cirrhosis [1]. Here, we report on 2 patients with alcoholic cirrhosis who were treated with TIPS placement.

\section{Case Reports}

Case 1

A 55-year-old woman presented with a history of well-compensated alcoholic cirrhosis (class A based on the Child-Pugh score) and no history of bacterial spontaneous peritonitis. However, the patient presented with episodes of upper gastrointestinal bleeding not attributed to Mallory-Weiss syndrome or esophageal varices. Due to recurrent hydrothorax episodes, which were nonresponsive to conservative treatment, the decision was made to use TIPS as treatment and it was performed without immediate complications. Prior to placement of the TIPS, the patient's renal function was normal (serum creatinine $0.6 \mathrm{mg} / \mathrm{dL}$ ) and an absence of hematuria or proteinuria was noted. Four months after placement, the patient was admitted for an anasarca episode which was refractory to pharmacological treatment. Serum C3 complement $(67 \mathrm{mg} / \mathrm{dL}), \mathrm{C} 4(10 \mathrm{mg} / \mathrm{dL})$, procalcitonin $(<0.10 \mathrm{ng} / \mathrm{mL})$, and IgG $(557 \mathrm{mg} / \mathrm{dL})$ levels were low, while IgA $(671 \mathrm{mg} / \mathrm{dL})$ and IgM (281 mg/dL) levels were high. The patient showed clinical anasarca along with hypoalbuminemia, hypercholesterolemia, and up to $21 \mathrm{~g}$ proteinuria in $24 \mathrm{~h}$. A transjugular renal biopsy revealed glomerular thickening of the capillary basement membrane, especially in the peripheral regions (Fig. 1a). Moreover, thickening of the matrix and mesangial cells with nuclei aggregation and focal mesangial interposition were also observed (Fig. 1a). Therefore, a diffuse membranous glomerulopathy concomitant with a mesangiocapillary immune complex glomerulopathy was diagnosed. At that time, the patient's serum creatinine level was $0.6 \mathrm{mg} / \mathrm{dL}$. However, despite intensive diuretic therapy, clinical anasarca persisted. Therefore, 2 weekly sessions of ultrafiltration were done for 6 months, and thereafter pharmacological treatment was continued until now.

At the time of writing, the patient had stage II chronic kidney disease with hypoalbuminemia $(2.5 \mathrm{~g} / \mathrm{dL})$, mild proteinuria $(2.6 \mathrm{~g} /$ $\mathrm{dL}$ ), hypertransaminasemia, cholesterol at the high end of the normal range, and serum creatinine levels ranging from 0.9 to $1.3 \mathrm{mg} /$ dL. No further episodes of liver alcoholic cirrhosis or decompensation were detected and the patient's Model for End-Stage Liver Disease (MELD) score was 10, mainly due to the reduced renal function. The patient's daily diuretic therapy included $250 \mathrm{mg}$ of spironolactone, $50 \mathrm{mg}$ of chlorthalidone, and $60 \mathrm{mg}$ of furosemide.

Case 2

This patient was a 54-year-old male with a history of active smoking and liver alcoholic cirrhosis with significant functional compromise (Child-Pugh class B) and episodes of ascites. Since diuretic treatment and repeated paracentesis did not improve the episodes of ascites, the patient was deemed to qualify for TIPS placement. Before placement, the patient exhibited stage III chronic renal disease (serum creatinine $2.7 \mathrm{mg} / \mathrm{dL}$ ) and urine sediments tested positive for hematite (100 cells per field) without proteinuria. Four months after TIPS placement, the patient exhibited an average proteinuria of approximately $6.4 \mathrm{~g}$ every $24 \mathrm{~h}$, rising to $11.5 \mathrm{~g}$ within 8 weeks, and persistent hematuria. The $\mathrm{C}$ reactive protein level was $3 \mathrm{mg} / \mathrm{L}$ and serum C3 and C4 complement levels were low (52 and $10 \mathrm{mg} / \mathrm{dL}$, respectively), while $\operatorname{IgA}(528 \mathrm{mg} / \mathrm{dL})$ and $\operatorname{IgG}(1,660 \mathrm{mg} / \mathrm{dL})$ levels were high and the $\operatorname{IgM}(173 \mathrm{mg} / \mathrm{dL})$ level was normal. At that time, the patient was placed under diuretic treatment. Eight months later, a renal biopsy revealed moderate hypercellularity and mesangial expansion with visible capillary lumens. Moreover, thickening of the basement membrane was found with focal mesangial interposition (Fig. 1b). In addition, immunofluorescence revealed mesangial IgA and C3 deposits.

The patient was diagnosed with mesangioproliferative glomerulonephritis and placed on the waiting list for a combined liverkidney transplant. The transplant was carried out 11 months later. After the transplant, the renal function improved (serum creatinine $1.2-1.4 \mathrm{mg} / \mathrm{dL}$ ), although the proteinuria persisted (3.0 g per $24 \mathrm{~h})$. In addition, the liver function was normalized. However, 6 months after the transplant, following an alcoholic cirrhosis relapse, the patient suffered an acute cellular graft rejection accompanied by anemia, a fracture of the ischial pubic ramus, and acute renal failure, which led to the patient's death.

\section{Discussion}

These were 2 cases of cirrhotic patients without a history of renal glomerular pathology in whom immune complex membranoproliferative glomerulonephritis (MPGN) developed after TIPS placement. In both cases, significant proteinuria appeared a few months after TIPS placement, and a renal biopsy showed histological alterations compatible with MPGN.

Glomerular diseases are common complications of end-stage liver disease such as cirrhosis. About $50 \%$ of hospitalized patients with cirrhosis present with acute kidney injury [2]. The most frequent diseases involved are mesangial glomerulonephritis with IgA depositions and membranous glomerulonephritis. Normally, hepatic endothelial and Kupffer cells are involved in the clearance of immune complexes [3]. In both cases, immune complex MPGN, which is related to an impaired clearance of immune complexes, was diagnosed [4]. Therefore, a decreased liver function could be responsible for these complications.

In case 1, the kidney function was normal and no proteinuria was present prior to TIPS placement. MPGN with heavy proteinuria was observed only after TIPS placement. In case 2 , the renal function was reduced before TIPS placement and worsened (with significant proteinuria) afterwards, although it should be noted that no proteinuria data before the TIPS was available. It is plausible that the portohepatic communication achieved by TIPS placement induced the MPGN via accumulation of

Immune Complex MPGN in TIPS

Med Princ Pract 2017;26:286-288 
Fig. 1. Light microscopy of renal tissue in patient 1 (a) and patient 2 (b) showing membranoproliferative changes. White arrows show mesangial interposition and hypercellularity, while black arrows highlight thickening of the glomerular basal membrane.
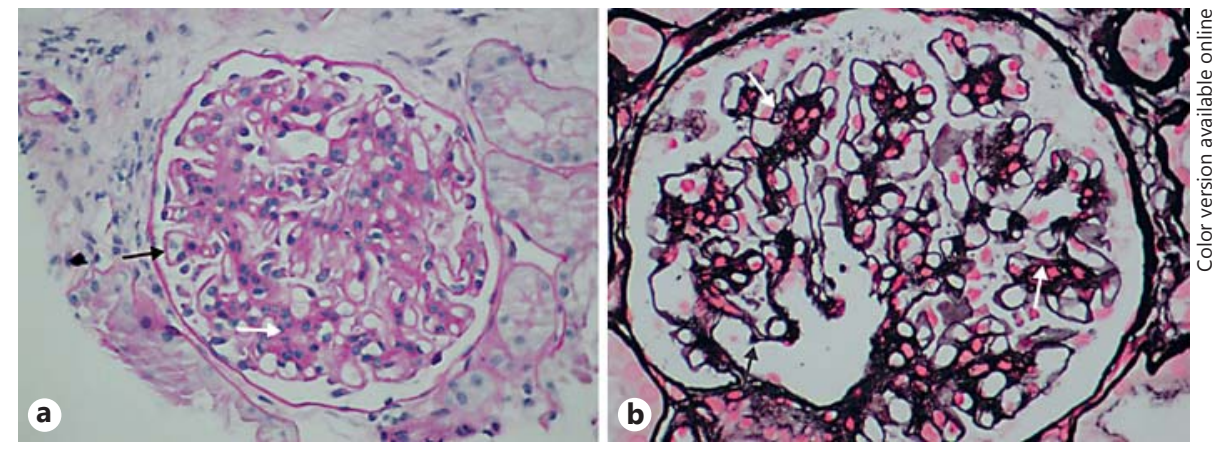

immune complexes that were no longer processed in the liver. Indeed, several cases have been previously reported in which immune complex MPGN was diagnosed in patients with portohepatic shunts such as portosystemic shunt surgery $[5,6]$ and in patients with a congenital portosystemic shunt $[7,8]$.

In the cases reported here, the patients developed immune complex MPGN within a short period of time after TIPS placement (i.e., 4 months). This is in contrast to the previously published cases in which a longer period of time (6-20 years) between portosystemic shunt insertion and MPGN development was reported [5-7]. Our patients suffered from alcoholic cirrhosis with portal hypertension, a severe disease accompanied by a large reduction in liver function and, therefore, a possible reduction in immune complex processing. Therefore, it seemed plausible that the early development of immune complex MPGN might have been related to the decreased liver function in addition to the TIPS placement, thereby rein- forcing the idea that the reduction of liver immune complex processing could be a factor in the development of type I MPGN.

\section{Conclusion}

The TIPS in one patient was successful without immediate complications, while the other patient was referred for a combined liver-kidney transplant. In both cases, immune complex MPGN might have developed after TIPS placement probably due to a reduced immune complex clearance. Therefore, physicians should be aware of the probability of kidney damage in patients receiving TIPS.

\section{Disclosure Statement}

The authors declare no conflicts of interest.

\section{References}

1 Colombato L: The role of transjugular intrahepatic portosystemic shunt (TIPS) in the management of portal hypertension. J Clin Gastroenterol 2007;41:S344-S351.

2 Karvellas CJ, Durand F, Nadim MK: Acute kidney injury in cirrhosis. Crit Care Clin 2015;31:737-750.

3 Kosugi I, Muro H, Shirasawa H, et al: Endocytosis of soluble IgG immune complex and its transport to lysosomes in hepatic sinusoidal endothelial cells. J Hepatol 1992;16:106114.
4 Sethi S, Fervenza FC: Membranoproliferative glomerulonephritis - a new look at an old entity. N Engl J Med 2012;366:1119-1131.

5 Soma J, Saito T, Sato H, et al: Membranoproliferative glomerulonephritis induced by portosystemic shunt surgery for non-cirrhotic portal hypertension. Clin Nephrol 1997;48: 274-281.

6 Smet AD, Kuypers D, Evenepoel P, et al: "Full house" positive immunohistochemical membranoproliferative glomerulonephritis in a patient with portosystemic shunt. Nephrol Dial Transplant 2001;16:2258-2262.
7 Karashima S, Hattori S, Nakazato H, et al: Membranoproliferative glomerulonephritis in congenital portosystemic shunt without liver cirrhosis. Clin Nephrol 2000;53:206211.

8 Okamoto N, Fukazawa S, Shimamoto M, et al: Remission of membranoproliferative glomerulonephritis associated with a noncirrhotic portosystemic shunt after percutaneous transhepatic portal vein embolization. NDT Plus 2009;2:228-232. 